\title{
Dangerous Schools and the Rise of Parentocracy
}

\author{
Daniel Madzanire \\ Great Zimbabwe University \\ Email: danielmadzanire@gmail.com \\ Rumbidzai Mashava \\ Great Zimbabwe University \\ Email: shabamashava@gmail.com
}

Accepted: September 30, 2012 Published: October 26, 2012

Doi:10.5296/jsr.v3i2.2568 URL: http://dx.doi.org/10.5296/jsr.v3i2.2568

\begin{abstract}
The study focused on how secondary schools that malfunctioned at the thick of economic crisis evoked parental involvement in Harare, Zimbabwe. Owing to the qualitative nature of the study, a case study research design was found to be more appropriate in order to describe in detail the rise of parentocracy. Face- to-face interviews and a questionnaire were used to gather data. 368 respondents constituted the population from which a sample of 63 participants was drawn. Following a detailed thematic analysis, it emerged from the study that parentocracy increased as schools underperformed. Recommendations were made for the government to address the challenges that are threatening pedagogy in order to lighten the burden on parents.
\end{abstract}

Keywords: malfunction, parentocracy, school, crisis

\section{Introduction}

The crisis period in Zimbabwe 2000-2008 marked by the controversial land reform reached its peak in 2008 (Raftopoulos and Savage, 2004). Bond and Manyanya (2003) refer to this period as Zimbabwe's plunge. This study however was confined to the economic decline during the period 2007-2009. Notably, the challenges that bedeviled the education fraternity were not only political but also economic. As the economic and political spheres declined so was the education sector. Primary, secondary and university sectors were caught up in the economic and political quagmire which had a ripple effect on all sectors of the society (Bond and Manyanya, 2003). This meant that the school purposes of which are intellectual, political, social and economic were adversely derailed (Sadovnik, 2004). Thus schools became dysfunctional and therefore dangerous for the nation.

Schools became dysfunctional in a number of ways. For instance, difficulty in attracting competent teachers due to low salaries (Ballantine, 2003; UNICEF, 2009) has a catastrophic 
effect on education especially in terms of examinations. Examinations demand thorough guidance by the teacher and diligent preparation on the part of the learner.

Transport and food problems, lack of public funding coupled by poor attendance by both teachers and learners incapacitated schools at the climax of the crisis period (UNICEF, 2009). Learner performance was grossly affected by poor attendance and a mass exodus of teachers to neighboring countries in search for better economic opportunities (Tevera and Crush, 2003; Sinyolo, 2008). Due to the economic and political decline the educational standards generally deteriorated.

A school that becomes dysfunctional is rendered dangerous not only to the learner but to the community and the nation as well. When such disastrous circumstances loom, the community and the nation do not just watch. Measures are taken to circumvent the threats. These may emanate from the government or the parents. In Zimbabwe at the peak of the economic challenges in 2008, the burden fell on parents as the government got incapacitated (UNICEF, 2009). The parents had to fork out a fortune on extra lessons as the country's education standards continued to plunge to mediocre levels.

As a result of the economic decline, the level of parentocracy rose remarkably. Fortier (2008) remarks that human beings remain creative both in times of peace and conflict. What is parentocracy? Brown in Macionis and Plummer (2008:661) defines parentocracy as "a system where a child's education is increasingly dependent upon the wealth and wishes of parents, rather than ability and efforts of pupils". Thus parents get increasingly involved in school business. They exercise a great deal of power. In Zimbabwe, parents sacrificed to pay incentives to teachers in order to raise their morale Ministry of Education Sport, Art and Culture (MOESAC, 2010). The incentive was granted by the Ministry of Education, Sport, Art and Culture at an official negotiable rate of $10 \%$ of the fees payable by the learner. Affluent schools offered hefty incentives which attracted staff. Non- affluent schools lost a great deal of competent staff either to affluent schools or to the diaspora as a result they were rendered dangerous. Parents opted to send their children to schools that were not only functional but could highly motivate their teachers by paying huge incentives (Chingombe and Chingombe, 2012). Teachers scrambled to teach at highly rewarding schools. As a result, a differential rewarding system for teachers with similar qualifications emerged. The schools that cannot afford hefty incentives for staff are a source of demotivation. In circumstances where schools fail to incentivize teachers they get demotivated and find it difficult to deliver (Chingombe, 2012). This may then culminate in underachievement which exposes a school to a lot of dangers. Given this scenario, access to education let alone achievement largely depends on the status of parents (Macionis and Plummer, 2008). The nation cannot allow the education system to collapse. In this regard, parentocracy illuminates as schools malfunction.

\section{Statement of the problem}

The study undertook to investigate the rise of parentocracy as schools become dangerous to 
their clientele.

\section{Objectives of the study}

The study was guided by the following objectives:

1. To establish circumstances which make schools dangerous.

2. To examine the causes of the rise of parentocracy as schools malfunction.

\section{Research Questions}

The study endeavored to answer the following questions:

1. What circumstances render schools dangerous?

2. How do parents react to malfunctioning schools?

\section{Theoretical Framework}

This study is largely informed by functionalism especially Durkhemian and Parsonian views on education. The basic assumption of functionalism is that society and institutions within society are made up of interdependent parts all working together, each contributing some necessary activity to the functioning of the whole society (Ballantine, 2003; Haralambos, Holborn and Heald, 2008). In other words, each institution plays a role for the benefit of the whole society. Thus, education as an institution contributes to the survival of the society. Functionalists are concerned with functions of schools in the maintenance of order in society.

\section{Durkheim's Views On Education}

Durkheim in his major works-Moral Education, The evolution of Educational Thought, and Education and Society, believes that education is critical in creating a moral unity necessary for social cohesion and harmony (Sadovnik, 2004; Ballantine and Spade, 2004)). Emphasis is on how schools foster morality in order to bring about order in the society. To enhance morality, schools must foster discipline (Haralambos, Holborn and Heald, 2008). Ballantine (2003) notes that one of the primary concerns by parents regarding schools is lack of discipline. Schools that lose grip on discipline generally malfunction. Ballantine (2003) cite Durkheim as saying "Discipline is the morality of the classroom, and without it the class is like a mob" (p.8). When schools relax on discipline, learning retrogrades and parents do not only raise their concerns but take corrective measures. Threats to the school fall back on the society. Hence the view that a school is a miniature society (Haralambos, Holborn and Heald, 2008; Macionis and Pummer, 2008).

Durkheim sees the major function of education as the preparation of young people for their adult roles in society via the transmission of norms and values (Haralambos, Holborn and Heald, 2008; Ballantine, 2003; Sadovnik, 2004). In essence, Durkheim in Ballantine and Spade (2004) defines education as "the influence exercised by adult generations on those that 
are not yet ready for social life" (p.8). Thus education socializes the young into the culture of their society. This transmission of culture occurs as teachers deliver lessons and guide learners on proper behavior.

Bennett deMarais and LeCompte in Sadovnik (2004) identify four functions of schooling in society. These include intellectual, political, social and economic functions. For Durkheim, schools become dysfunctional once the aforementioned roles are not properly executed (Ballantine and Spade, 2004). Parents expect schools to perform their roles to the fullest. Otherwise schools that do not fulfill their mandate may be regarded as harmful by its clients.

\section{Parsons' Conception Of Education}

Parsons agrees with Durkheim that schools are miniature societies that socialize the young into the norms and values of the society (Haralambos,Holborn and Heald, 2008). Parsons however, goes a step further to highlight some important aspects of education that Durkheim overlooks. These include the selection and allocation role as well as bridging of the gap between the expectations of the society and the actual school performance (Ballantine, 2003). These crucial functions of the school fuel parents to get involved in affairs of the school to the extent of exercising their power.

Parsons believes that education selects individuals for various occupational opportunities (Meighan and Siraj-Blatchford, 2003; Macionis and Plummer, 2008). Parents are concerned about the selective and allocative role of the school because it determines the future destiny of their children. Parsons maintains that the process of selection is characterized by the values of achievement and equality of opportunity. These values determine income, status and position in the stratified society. Parents are interested in whether their children will achieve in education and progress in society. This may justify why parents send their children to school A rather than B. Schools where children do not excel are a concern for parents.

Parents value achievement of their children hence their concern about the extent to which schools deliver. Factors that generally derail learning include: use of drugs, lack of discipline, lack of proper financial support, difficulty in attracting competent teachers, poor curriculum standards and large school (overcrowding) (Ballantine,2003). As schools get dangerous, parents take measures to rescue their children.

\section{Literature On Parental Involvement}

There are a variety of factors militating against smooth discharge of duty by schools. These are economic, political, and social in nature. Catastrophic schools are identified by their failure to live up to the purpose for which they were established. Parents expect schools to produce desired results. Meighan and Siraj-Blatchford (2003) cite Durkheim as saying, "The man who education should realize in us is not the man such as nature has made him but as society wishes him to be ... It is society that draws for us a portrait of the kind of man we 
should be,..." (p.254).

Thus society shapes an individual according to its blue print. If schools as institutions fail to produce citizens that satisfy societal expectations, they attract attention of the society. Sadovnik (2004) and Berns (2007) identify seven functions expected of the school by the society. These include: inculcating intellectual and social experiences, transmission of the cultural heritage, response to ethnic diversity, sensitivity to religious pluralism, adaptation to social change, fostering strong discipline and safety, and family involvement in school affairs.

As a socializing agent, the intellectual purpose of the school is to teach basic cognitive skills such as reading, writing and mathematics (Sadovnik, 2004). In addition, schools also help students to acquire higher order thinking skills such as analysis, evaluation and synthesis which are pertinent in examinations. These cognitive skills characterize children as individuals and shape their abilities to perform adult roles (Berns, 2007). Students who are good at commercials will eventually occupy roles in the business sector while those who pursue sciences will become medical personnel. Viewed in this light, parents expect schools to sharpen the cognitive faculties of their children along lines of their wishes. Schools that produce illustrious results churn out students who occupy prestigious positions in society. Parents prefer to send their children to schools that empower them (Olsen and Fuller, 2003 in Berns, 2007).

The primary function of education from a parental perspective is the transmission of cultural heritage (Sadovnik, 2004; Haralambos, Holborn and Heald, 2008; Berns 2007). That is "the accumulated knowledge, values, beliefs and customs of the society" (Berns, 2007:216). The object here is to transmit culture from generation to generation (Macionis and Plummer, 2008; Ballantine and Spade, 2004). In his appeal to the Zimbabweans in the Diaspora to support the collapsing education sector, the Minister of Education, Sport, Art and Culture David Coltart indicated that, current literature did not portray the history of Zimbabwe accurately (UNICEF, 2009). The Minister persuaded the Diasporas to come forward and re-write Zimbabwean history comprehensively. History of Zimbabwe was declared compulsory at ' $O$ ' Level in a bid to transmit and preserve the nation's cultural heritage. Great Zimbabwe University made tremendous efforts to preserve Cultural heritage by establishing the centre for cultural and heritage studies. The mandate of the centre is to execute activities, programmes and initiatives that engender preservation of culture.

A school should be able to respond to ethnic diversity expeditiously. Generally, a school in a multi-ethnic society recognizes the co-existence of different cultural groups (Lemmer, Meier and Van Wyk, 2006; Ndamba and Madzanire, 2010). Berns (2007) encourages 'unity in diversity'.

Sensitivity regarding religious pluralism is advisable so that schools function as expected. Religious values may clash with educational goals (Schaefer, 2010). The Shangani ethnic group in Sengwe, Zimbabwe withdraws children from school during term time in order to 
fulfill rituals which their tradition obliges them to do (Madzanire, 2011). School administrators may clash with the Shangani people if they interfere with their ritual. There is need to balance religious values, school culture and societal culture.

In a society, change is inevitable. It is prudent for a school to adapt to specific developments such as technology (Macionis and Plummer, 2008). Society now demands computer literate students. Commensurate with technological advances, schools should integrate technology with instruction. Oppenheimer (2007) avers that as a tool, a computer can present and store information apart from motivating and rewarding students to construct their own knowledge. Group discussions can be carried out via e-mail. The curriculum and method of instruction change as schools prepare children for the world of work (Madzanire, 2011). What it means is that schools that do not teach computers produce half-baked students who do not fit squarely into the society. Such a dysfunction may propel parents to send their children to school A rather than B.

To function successfully, school environment must be safe (Berns, 2007). Violence and substance abuse that may emanate from the community should be controlled by the school. Sutherland in Henslin (2003) argues that deviance is learnt from one's neighborhood. Some learners have access to guns and knives. It is the duty of a school to guarantee safety. Schools that are violence-prone risk losing learners and staff.

To ensure successful execution of duty, schools should involve parents in the affairs of the school (Berger, 2003). Families that value education are likely to communicate the importance of education to their children. Such parents are likely to supervise their children's homework and respond to teachers' request for behavioral change. Studies reveal that parental involvement is related to a child's school performance (Berger, 2003; Berns, 2007). In fact, family involvement rather than socio-economic factors is believed to be a better predictor of performance (Berns, 2007).

Parents can be involved in decision-making and partnership in form of home guidance to help their children learn. Comer in Ballantine and Spade (2004) found that involving parents of disadvantaged children overcame parent distrust of the school. Parents need information pertaining to the performance by their children as well as developments at a school. When parents develop confidence in the school, they then support it.

\section{Methodology}

\section{Research Design}

This study is a case study which is largely qualitative. In a case study, the researcher typically observes the characteristics of an individual unit. This could be a child, a clique, a school or a community (Cohen and Manion, 2010). The researchers found the case study suitable owing to its emphasis on describing in detail what goes on in a particular activity. In this case, 
the rise of parentocracy as schools malfunction was investigated. Focus was on two secondary schools. This design enabled the researchers to make a thick description of the rise of parentocracy (Creswell, 2008).

\section{Selection Of Participants}

The research was conducted at Kuwadzana and Dzivaresekwa high schools in Harare, Zimbabwe. Purposive sampling technique was used (Chilisa and Preece, 2005). Eight (8) school administrators, 15teachers, 20 parents and 20 learners were considered as key sources of information pertaining to the rise of parentocracy as schools malfunction.

\section{Research Instruments}

A semi-structured interview schedule was developed by researchers in order to gather qualitative data. Two themes were covered: circumstances that make schools dangerous and Parental reaction to malfunctioning schools. Interviews permitted the researchers to collect both verbal and non-verbal data (Fielding, 2003). Furthermore the researchers could probe for clarity where ambiguity was a hindrance (Creswell, 2008). Researchers conducted face-to-face interviews with 20 parents and 8 school administrators.

For 20 learners and 15 teachers an open-ended questionnaire was used. The researchers managed to capture the opinions of the participants at the same time guiding them to stick to questions pertinent to the research (Chilisa and Preece, 2005). The open- ended questionnaire was preferred because data that were gathered could be easily summarized, compared and analyzed. The adherence to prepared questionnaire and interview schedule enhanced content validity. That is, the ability of the aforementioned instruments to measure what they purport to measure (Haralambos and Holborn, 2010).

\section{Findings And Discussion}

\section{Circumstances That Make Schools Dangerous}

Eleven $(73 \%)$ of the 15 teachers who responded to a questionnaire indicated that schools were not able to maintain discipline. Both teachers and learners frequently absented themselves from school. This meant that learners were disadvantaged as some crucial lessons were not covered. UNICEF (2009) confirms that poor attendance was one of the contributory factors that incapacitated schools in Zimbabwe during the crisis period. The school should maintain discipline by complementing disciplinary efforts fostered in the home by the parents.

Thirteen (87\%) teachers admitted that during the crisis period schools could not retain experienced staff let alone basic material resources. When probed further, $9(60 \%)$ teachers revealed that they at one point migrated to the diaspora in search of greener pastures. The 
shrinking of Zimbabwean economy from 2000-2009 resulted in internal brain drain (Sinyolo, 2008; Tevera and Crush, 2003). The Minister of Education, Sports, Art and Culture Senator David Coltart lamented that between 2007 and 2008 Zimbabwe lost about 20000 teachers mostly to neighboring countries (MoESAC, 2010). Those who opted to stay abandoned full commitment to their professional duties by engaging in 'private jobs' as foreign currency dealers or taxi drivers. They only returned when the Global Political Agreement (GPA) ushered in the multicurrency system. Twelve (80\%) teachers indicated that they thrived on small scale cross border trading. In this regard, Root (2010) observes that employees engage in secondary activities after work to supplement their meager incomes. Ten $(67 \%)$ teachers spent precious teaching time on the streets exchanging foreign currency illegally. A significant number of teachers $8(53 \%)$ indicated that they transferred to schools that could either offer attractive incentives or that were convenient in terms of transport. Chingombe and Chingombe (2012) indicate that during the crisis period, staff turnover was high.

All teachers $15(100 \%)$ agreed that their morale during the crisis period was very low. This meant that teachers could not discharge their duties to the best of their capacity. In the same light, UNICEF (2009) reported that low morale on the part of the teacher incapacitated the Zimbabwean education sector.

To worsen the state of schools during the crisis period, 6(40\%) teachers were forced to abandon their stations as they succumbed to political pressure. Learners suffered as they prepared for examinations without guidance.

Teachers pressurized parents to pay them incentives by streaming learners into two groups, those that could pay incentives in one group and those that could not pay in another. One teacher $(7 \%)$ had this to say: 'Some pupils were grouped according to whether they paid incentives or not. Those who paid incentives were taught but those who did not pay were just taught'.

Learners whose parents could pay incentives were better prepared for examinations as teachers were desperate to squeeze out cash from struggling parents at whatever cost. Monetary rewards systems are known to play a significant role in employee motivation (Cenzo and Robbins, 1998). Teacher demotivation was high during the crisis period as most civil servants lived below the poverty line.

Eight school administrators (100\%) who were interviewed concurred that low performance in general, lack of discipline, poor attendance by both teachers and staff, lack of experienced staff as well as lack of material resources rendered schools dangerous. Dangerous in the sense that learners like sheep without a shepherd were left unsupervised. Without supervision, as observed by Akinpelu (1981) learners can choose to play the whole day and benefit nothing. Like teachers, administrators indicated that performance was remarkably poor during the crisis period. Two (2) (25\%) administrators indicated that pass rate for their respective schools dwindled to $5 \%$ in 2008 . One $(12.5 \%)$ administrator revealed that a marginal number 
of students (2\%) managed to register for external examinations in 2008. On the political scene in 2008, 6(75\%) administrators indicated that learners were forced to participate in politics. Learners were stage managed to attend rallies where hate speech was used against teachers who were accused of perpetuating the interests of the opposition. This development stifled the relationship among teachers, learners, administrators and politicians. One $(12.5 \%)$ administrator acknowledged that some teachers were compelled by prevailing political circumstances to abandon their stations as alluded to by teachers. Education in general was heavily politicized (Moyo, 2012). This scenario coupled with the collapsing economy incapacitated the education sector (UNICEF, 2009).

Twenty learners (100\%) who were asked to indicate circumstances that render schools dangerous echoed the teachers and administrators' observation that schools did not have enough teachers. The bulk of Mathematics and Science teachers trekked to South Africa (Mosley et al, 2009). Few teachers who remained were absent from duty most of the time. This meant that learners spent precious learning time alone without guidance. This result confirms the claim by $2(25 \%)$ administrators that pass rate during the crisis era hit a record of $5 \%$.

Twelve $(60 \%)$ learners could not attend school daily. When they were probed further, they attributed their problem to lack of bus fare, few commuters that were plying their route to school, teachers who were on strike, and lack of school fees which saw them sent back home. What started as an economic crisis turned out to be an educational one. To circumvent their predicament and possibly augment their family income, the same number of learners indicated that they sometimes got involved in work such as selling vegetables and fruit. Robb (2002) observed that when people are in crisis they are able to analyze their poverty and find a solution to it. Fortier (2008) remarked that human beings remain creative both in times of peace and conflict.

Twelve (60\%) learners just like teachers and administrators, indicated that there was little discipline in schools. Two (10\%) learners admitted that there was no discipline during the crisis period. This result confirms Durkheim's observation that discipline is the morality of the classroom (Macionis and Plummer, 2008).

A significant number of learners 7 (35\%) could not register for external examinations since their parents were incapacitated. This implied that learners lost a great deal of precious time. The circumstances forced them to exit secondary education without credentials.

\section{Parents' Reaction To Malfunctioning Schools}

Twenty (20) parents were interviewed in order to establish their degree of involvement in school affairs amid the crisis. All the parents (100\%) agreed with the teachers, learners and administrators that at the peak of the crisis in Zimbabwe, there was no meaningful learning due to incessant strikes by teachers, absenteeism by both teachers and learners, low morale on 
the part of the teacher which was propelled by low salaries. This result was also confirmed by UNICEF (2009). The parents had no option but to carry the burden.

Since the education of children was incumbent upon the parents, $8(40 \%)$ parents indicated that they were forced to pay for extra lessons out of their hard earned money. The fact established above that teachers sidelined learners who could not pay for incentives and extra lessons, propelled parents to fork out money for extra lessons. In connection, all administrators (8) (100\%) and 7 (35\%) learners admitted that a small number of parents could pay teachers for their children to get extra lessons. This meant that only affluent parents could fund their children's studies. Resources available to families tend to differ (Manduvi-Moyo and Lewin, 2001). Although the situation threatened to weaken parental involvement in school affairs, parents did not relax. They did what they could under the circumstances.

In an effort to rescue their children who were no longer receiving adequate instruction, parents paid incentives for teachers in a bid to motivate them. Twelve $(60 \%)$ parents indicated that they paid incentives. Two (10\%) parents paid incentives in kind specifically in form of maize and beans. One teacher $(5 \%)$ who is small scale cross border trader revealed that she paid incentives in form of food hampers and soap. Cameron and Pierce (2005) observe that non-monetary incentives are effective and legitimate. This is especially so in the case of Zimbabwe during the crisis period because supermarkets were empty. In this regard, parents got involved in school affairs albeit the deep seated crisis.

In a bid to register their concern, some parents identified schools that delivered and transferred their children there. Three (15\%) parents acknowledged that they at some point transferred their children to schools they perceived to be better. This result echoes Sadovnik (2004)'s observation that parents expect their children to achieve in education. This explains why parents are keen to associate themselves with schools that produce results.

Apart from paying for teacher incentives and extra lessons, parents had to provide learning resources like textbooks and stationery all of which were difficult to get. Thirteen $(65 \%)$ parents revealed that the circumstances during the crisis period compelled them to provide material resources needed for their children to learn. As schools ran out of basics like pieces of chalk, the burden fell on parents. One parent (5\%) narrated the situation as follows:

I struggled to raise school fees for my son. As soon as I finished paying for school fees, inflation wiped it to nothing. The school asked me to top up the fees in kind. I bought basic materials such as chalk, soap, rice, textbooks and stationery, mealie-meal and beans. I struggled to acquire these necessities.

This meant that parents registered their commitment to school affairs in an extraordinary way. That is, by topping up fees in kind. Zvobgo (1999) acknowledges that parents can offer their services in place of fees. Those with skills can contribute their labor to the school. The crisis propelled the degree of involvement on the part of the parents. In the same vein all administrators (8) (100\%) observed that while some parents could mobilize 
resources, others were giving up. It was not the case that all parents were concerned, some were spectators.

In tandem with learners, $15(75 \%)$ parents indicated that they attended consultation days and meetings notwithstanding the crisis. Besides that, 8(40\%) parents could supervise their children's home work. The same number of parents coincides with the abovementioned number of parents who revealed that teachers professionally compelled them to pay for extra lessons. The parents who could pay for extra lessons had their children assigned homework which they supervised. What it meant was that affluent parents were more involved in education than non-affluent ones owing to the fact that resources that parents could mobilize vary. This result confirms Manduvi-Moyo and Lewin (2001)'s observation that resources available to communities vary. Poor communities fail to mobilize resources and fully participate in school activities. This has tended to perpetuate inequalities that existed before.

\section{Recommendations}

The study makes the following recommendations:

- Parents should be more involved in the education of their children since success in education is not solely dependent on economic factors.

- The Ministry of Education, Sport, Art and Culture should rationalize incentives such that all teachers equally benefit from the facility in order to avoid a differential reward system.

- In line with their call to duty, teachers and administrators should create a conducive learning environment notwithstanding crisis.

\section{Conclusion}

The study revealed that the economic crisis which hit Zimbabwe in the period 2007-2009 nearly led to the collapse of the education system which rendered schools dangerous. Schools failed to deliver their mandate as they were closed, understaffed or under resourced. The departure of teachers to neighboring countries due to economic difficulties left schools incapacitated. Parents too, were badly hit. However, to a larger extent parents managed to revive the ailing education system through a variety of strategies which included both material and non-material support to the school.

\section{References}

Akinpelu, J.A. (1981) An Introduction to Philosophy of Education. London: Macmillan

Ballantine, J.H. \& Spade, J.Z. (2004) School and Society: A Sociological Approach to Education . Belmont: Thomas Wadsworth

Ballantine, J.H. (2003) The Sociology of Education: A Systematic Analysis. New Jersey: 
Prentice-Hall

Berns, R.M. (2007) Child Family, School Community: Socialization and Support. Belmont: Thompson Wadsworth

Berger, E.H. (2003) Parents as Partners in Education: Families and Schools Working Together. New Jersey: Prentice-Hall

Bond, P. \& Manyanya, M. (2003) Zimbabwe's Plunge Exhausted Nationalism, Neoliberalism the Search for Social Justice. Harare: Weaver Press

Cameron, J. \& Pierce, W.D. (2005) Academic Exchange Quarterly. New York: Harper Collins

Cenzo, D.D. \& Robbins, S.R. (1998) Human Resources Management. New York: John Wiley and Sons

Chilisia, B. \& Preece, L. (2005) Research Methods for Adult Educators in Africa. Capetown: UNESCO and Pearson Publishers

Chingombe, A. (2012) Impact of Incentives at Great Zimbabwe University: Effects of Incentives on Job Performance. Berlin: LAMBERT Academic Publishing

Chingombe, S. \& Chingombe, A. (2012) Impact of Socio-Economic Factors on Pedagogical Practice in Harare: Socio-Economic Factors' Impact on Teaching. Berlin: LAMBERT Academic Publishing

Cohen, L. \& Manion, L. (2010) Research Methods in Education. London: Routledge

Creswell, J.W. (2008) Research Design: Qualitative and Quantitative Approaches. London: Sage Publications

Fielding, M. (2003) Effective Communication in Organization: Preparing Messages that Communicate. Cape Town: Juta and Company

Fortier, A. (2008) Culture and Conflict: Introduction. Retrieved 11 May 2012 from http://www.powerofculture.nl/en/specials/culture-and-conflict/introduction.

Haralambos, M.; Holborn, M \& Heald, R. (2008) Sociology: Themes and Perspectives. London: Collins Educational.

Henslin, J.M. (2003) Essentials of Sociology: A- Down -to -Earth Approach. Boston: Allyn and Bacon 
Lemmer, E.M., Meier, C. \& Van Wyk, J.N. (2006) Multicultural Education: An Editors' Manual. Pretoria: Van Schaik

Macionis, J.J \& Plummer, K. (2008) Sociology: A Global Introduction. Edinburgh: Pearson Education

Madzanire, D. (2011) Multi-ethnic Education in Zimbabwe: A Critical Reflection. Berlin: LAMBERT Academic Publishing

Manduvi-Moyo, T. \& Lewin, K. (2001) Financing Secondary Education in Zimbabwe, Acess, Equity and Efficiency Revisited. In: K. Lewin and F. Caillods (Eds) Financing Secondary Education in Developing Coutries, Strategies for Sustainable Growth. Paris: UNESCO

Meigham, R. \& Siraj-Blatchford (2003) A sociology of Educating. London: Continuum

MoESAC (2010) Minister's Annual Report. Harare: Government Printers

Moyo, R. (2012) 'Coltart Laments BEAM's Failure' Retrieved 30-04-2012 from http://www.newsday.co.zw

Mosley, P., Suleman, A. \& Chiripanhura, B. (2007) Escape Routes from Rural Poverty Trap: Evidence from Three African Countries. Paper Presented at CSAC Conference on Economic Development in Afrca, Oxford

Ndamba, G.T. \& Madzanire, D. (2010) Ethnic Diversity and the Dilemma of Adopting the Local Language of Instruction in Sengwe Primary Schools,Zimbabwe. In Zimbabwe International Journal of Languages and Culture, Vol 1 Number 2 December 2010.pp65-76.

Raftopoulos, B. \& Savage, T. (2004) Zimbabwe Injustice and Political Reconciliation. Harare: Zimbabwe Weaver Press

Root, G.N. (2010) The Advantages of Incentive Plan. New York: Harper Collins

Robb, C.M. (2002) Can the Poor Influence Policy: Participatory Poverty Assessments in the Developing World. Washington DC: The World Bank and IMF

Sadovnik, A.R. (2004) What is Sociology of Education? Theories in the Sociology of Education Belmont: Thompson Wadsworth

Sinyolo, D. (2008) Strategies for Reviving Zimbabwe's Education System. Retrieved on 03-09-2010 from http://www.newsday.co.zw 
Schaefer, T.R. (2010) Sociology. New York: McGraw-Hill

Tevera, D. \& Crush, J. (2003) The New Brain Drain from Zimbabwe. South African Migration Project Policy Series, No 29. Cape Town SAMP

UN News Centre, (2009) UNICEF Urges Action to Tackle Zimbabwe's Education Crisis. Harare: UNICEF

Zvobgo, J.R. (1999) The Post Colonial State and Educational Reform: Zimbabwe, Zambia and Botswana . Harare: ZPH 